\title{
Fluorometry in application to fingerprint of petroleum products present in the natural waters
}

\author{
Emilia Baszanowska ${ }^{*}$ and Zbigniew Otremba
}

\begin{abstract}
Background: This study analyses the possibility of optical detection of trace amounts of oil in natural waters. Since petroleum and its derivatives induced by ultraviolet light exhibit a high intensity of fluorescence, this phenomenon can be used to detect petroleum products penetrating both the surface and subsurface waters. The challenge is to discriminate the fluorescence signal originating from petroleum substances from the total signal originating from both petroleum products and the natural substances.

Results: Issues connected with fluorescence methods of detection of oil substances diffused in aquatic environment are analysed. Based on fluorescence spectroscopy, fluorometric indices of petroleum products for two forms (dissolved in n-hexane and dispersed in water) are discussed. The excitationemission spectra (EEMs) were determined in the range of excitation wavelengths 240-450 nm and 270-600 nm for emission. Selected parameters of oil fingerprinting are discussed: similarity ratio, intensity ratio and wavelength-independent fluorescence peaks $\left(E x_{\max } / E m_{\max }\right)$. The latter was compared with the typical fluorescing natural marine residues.
\end{abstract}

Conclusions: The results indicate that $E x_{\max } / E m_{\max }$ and intensity ratio appear to be efficient indices for the discrimination of oil pollution from autochthonous seawater fluorescent substances.

Keywords: Excitation-emission spectra, Oil pollution, Oil-in-water emulsion, Dissolved oil, Seawater

\section{Background}

When a petroleum substance comes into contact with the aquatic environment, a surface film begins to form. Moreover, oil is partially transported into the water column in the form of oil droplets (spontaneously or as a result of the use of dispersants) or as dissolved chemical compounds rinsed out of oil. In a typical case, when an oil spill occurs on the sea surface as an oil film, SAR (Synthetic Aperture Radar) satellite radar system or airborne radar SLAR (Side-Looking Airborne Radar) [1] provide the best chance of rapid detection of such oil pollution (in Europe, for example, it is the CleanSeaNet system operated by the European Maritime Safety Agency (EMSA) [2]. Further, when an oil spill is detected, accurate tracking of its spread is available using standard surveillance equipment. Unfortunately, these methods are unhelpful for chronic or multi-point pollution, which usually occurs along maritime traffic routes or in port vicinities.

\footnotetext{
* Correspondence: eba@am.gdynia.pl

Physics Department, Gdynia Maritime University, Gdynia 81-225, Poland
}

Therefore, only if the oil spot is sufficiently large can its movement be seen by satellite equipment such as SAR [3] or airborne visual tracking using observance geometry involving the direction of camera observation in various planes of light polarization in relation to the directional distribution of the downward solar light [4]. Moreover, if sampling is possible, measurements can then be carried out in a laboratory, for example, to determine the oil chemical composition or possible separation markers to establish the pollution source $[5,6]$.

If petroleum products in water are considered, it is necessary to take into account possible modification of those substances after their contact with the aquatic environment. Therefore, the efficiency of estimating the amount and extension of the presence of oil pollution has to be considered, including the transformations of the chemical composition as well as the physical-chemical features of petroleum substances in the marine environment. The time-scale of oil pollution evolution in seawater and the time in which oil residues are generally 
measurable both depend on the form of the current oil-water system (surface oil film, suspension of oil droplets or individual hydrocarbon molecules dissolved in water or, predominantly, all forms together). Moreover, the environmental conditions (solar light, wind, surface waves, water and air temperature and even salinity) influence oil pollution evolution in seawater. It is natural that insightful (yet time-consuming and expensive) specialized equipment might be supported by innovative, simple methods to detect oil pollutants. Moreover, the challenge is to find an efficient method to monitor oil residuals.

There are a variety of techniques used to study the complex structure of petroleum products (including fluorescence) since oils contain fluorophore centres which are typically positioned in mono- and polycyclic hydrocarbons. The light spectrum emitted by fluorophores can be modified by other processes, mainly light absorption (by various oil compounds) or even secondary fluorescence [7].

However, the most important is that oil affects the fluorescence spectra generated by the natural constituents of seawater. For low oil concentrations, it is difficult to separate the fluorescence of the natural seawater components from the fluorescence of hydrocarbon compounds originating from oil pollution. Taking this into account, the long-term scale monitoring of the spatial and seasonal changes in the natural components of seawater, such as chlorophyll, dissolved organic matter (DOM) and so-called coloured-dissolved organic matter, denoted as CDOM $[8,9]$, would be useful to interpret the spectra of both natural and man-made fluorescing substances.

For a description of the individual constituents of seawater, several techniques based on fluorescence spectroscopy have been developed to detect and identify the seawater constituents and monitor long-term changes. Particular components of natural seawater exhibit both fluorescence and absorption properties characteristic for appropriate excitation and emission wavelengths. Coble et al. described the absorption spectrum as well as the fluorescence spectra based on excitation-emission spectra (EEMs) [10-12]. The position of specific points, described as the typical fluorescence peaks for CDOM of these peaks, varies for inshore and offshore waters and rivers as well as coastal estuaries $[13,14]$. It is also essential that the fluorescence bands of oils overlap with bands of light absorption by chlorophyll and CDOM (which may be a result of deformation of the fluorescence spectrum in some cases) [15-19]. Therefore, the optical properties of both natural seawater constituents and oil substances should be considered in building an efficient model for tracking CDOM or marine phytoplankton and should enable a quantifiable assessment of basic natural and human-induced processes in marine and other natural waters [20].

This paper presents the excitation-emission spectra for two selected types of oils, as representatives of lubricant oils potentially found in the marine environment due to their use in shipping engines. The EEM spectra of oils were determined for different oil concentrations, which also allowed the wavelength-independent fluorescence peaks to be determined. Comparison of the spectroscopic features of lubricant oils in the two following different forms of oil: oils dissolved in n-hexane and an oil-in-water system (an oil suspension in the water), are discussed in relation to the natural constituents of seawater which usually are degradation products of biological organisms. Moreover, wavelength-independent fluorescence parameters and intensity ratios (considered to be sensitive for oil quantities) were analysed to identify oil in bulk water, based on EEM spectra.

\section{Method}

\section{Oil samples}

Two lubricant oils which are representative of marine ship engine systems were applied: Marinol 1240 and Cyliten $\mathrm{N}$ 460. Marinol, in comparison with Cyliten, visually exhibits a brighter shade of brown and is relatively clear and more transparent, whereas Cyliten is brighter in UV-light (as Fig. 1 illustrates). N-hexane (for analysis, $96.0 \%$ purity) was applied as an oil solvent to prepare samples placed in quartz cuvette. The several individual oil concentrations for dissolved oil samples were prepared, respectively, $20 \mathrm{ppm}, 50 \mathrm{ppm}, 230 \mathrm{ppm}, 280 \mathrm{ppm}$. The use of diluted oil in n-hexane relates to a practical aspect, which is the use of this solvent to extract oil substances from water previously sampled from the natural environment to determine the concentration of oil in the natural waters [21].

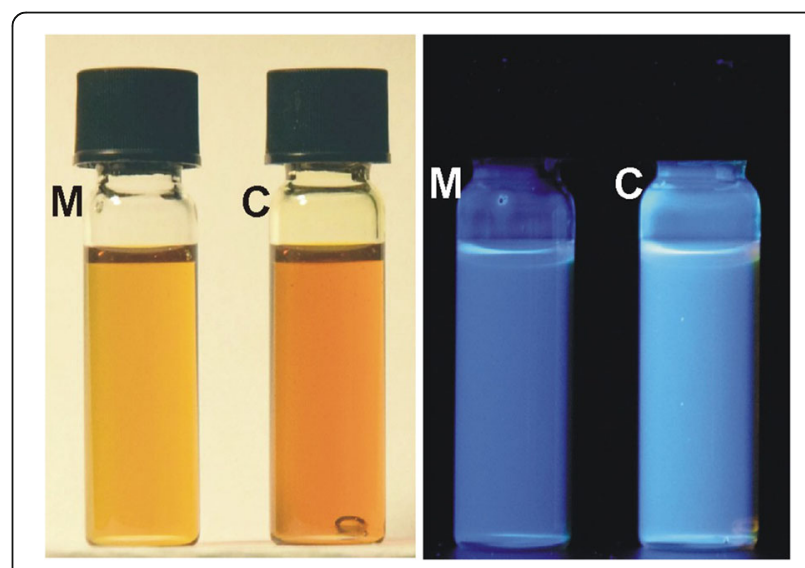

Fig. 1 Samples of studied oils Marinol (M) and Cyliten (C) - view in VIS (left) and in UV (right) 


\section{Measurement and apparatus}

An Aqualog Horiba spectrofluorometer was applied to measure the three-dimensional excitation-emission spectra (EEMs) of oil samples for both types of oil.

For EEM measurements, the following measurement parameters were applied: excitation wavelength from $240 \mathrm{~nm}$ to $600 \mathrm{~nm}$ with a $5 \mathrm{~nm}$ sampling interval, emission wavelength from $212.75 \mathrm{~nm}$ to $622.97 \mathrm{~nm}$ with a $1.623 \mathrm{~nm}$ sampling interval, $5 \mathrm{~nm}$ excitation slit, $5 \mathrm{~nm}$ emission slit.

Raman and Rayleigh scattering to yield a digital matrix of excitation-emission spectra was automatically removed using the software package of the spectrofluorometer.

\section{Fluorescent parameters}

To improve the analysis of measured results, fluorescence parameters were defined and calculated, respectively:

- the similarity ratio $\mathrm{s}_{\mathrm{ab}}$ - defined by formula (1) below:

$$
\mathrm{s}_{a b}=1-\frac{\sum_{i j}\left|w_{i j}^{a}-w_{i j}^{b}\right|}{\sum_{i j} w_{i j}^{a}+\sum_{i j} w_{i j}^{b}}
$$

In formula (1) the indexes "ij" refer to relative columns and rows in tables representing spectra "a" and " $b$ ", and the quantities $w_{i j}^{a}, w_{i j}^{b}$ refer, respectively, to normalised elements of the EEM matrix of the reference oil solution "a" and the compared solution " $\mathrm{b}$ ". $\mathrm{S}_{\mathrm{ab}}$ ranges from 0 (absolutely differ) to 1 (identical).

- the intensity ratio $\left(I_{\text {ratio }}\right)$ expressed by formula (2) below:

$$
I_{\text {ratio }(335 / 320)}=\left[\frac{I\left(\lambda_{E m=335}\right)}{I\left(\lambda_{E m=320}\right)}\right]_{\lambda_{E x=242.5}}
$$

where $\lambda_{E m}, \lambda_{E x}$ describe respectively, emission wavelength and excitation wavelength.

\section{Results}

Figure 2 presents the shapes of EEMs for two concentrations of oils diluted in hexane $(20 \mathrm{ppm}$ and $280 \mathrm{ppm})$. Significant changes in the shape and intensity of the main peak with an increasing concentration of oil were more distinct for Cyliten than for Marinol. On the other hand, an increase in accumulated fluorescence (the integral over all wavelengths of excitation and emission) for those two concentrations was greater for Marinol (530 \%) than for Cyliten (160\%). However, the most relevant information was found in the shape of the EEMs independent of the fluorescence intensity (normalised to the maximum value). The normalized excitation-emission matrices in a two-dimensional plane (2D) are shown in Fig. 3, where the tendencies to transform the EEM spectra caused by changes in oil concentration are visible. As mentioned earlier, the intensity of the maximum fluorescence increased for both oils when the concentration of oil increased, although the excitation and emission wavelengths related to maximum fluorescence (Marinol: excitation $242.5 \mathrm{~nm}$, emission $335 \mathrm{~nm}$; Cyliten: excitation $242.5 \mathrm{~nm}$, emission $348 \mathrm{~nm}$ ) remained constant in the range of concentrations studied. In the lowest concentrations, apart from the main peak, the lowest peak also appears (Marinol: excitation $275 \mathrm{~nm}$, emission $315 \mathrm{~nm}$; Cyliten: excitation $265 \mathrm{~nm}$, emission $320 \mathrm{~nm})$.

\section{Discussion}

Using the fluorescence technique, oil can be detected directly in the water (in situ or in the water sample) or in an extract (i.e. in n-hexane). However, based on the florescence spectra of seawater, the challenge is to confirm the presence of oil. To solve this issue, a key role is played by the specific shape of the fluorescence spectrum of oil. To compare the abovepresented EEMs for oil which was diluted in the solvent ( $n$-hexane) with the EEMs of oil which were emulsified in water, the results of the former measurements already partially discussed by Baszanowska et al. [22] were used, i.e. EEMs of water contaminated with the same oil as described above, but in the form of a suspension in clear (demineralized) water.

Normalized (as in Fig. 3) EEMs of oil-in-water suspensions for various concentrations are presented in Fig. 4. The spectra appear to be clearly different, since for both kinds of oil two peaks for the lowest concentrations are visible (in EEMs area: excitation from $240 \mathrm{~nm}$ to $280 \mathrm{~nm}$, emission from $380 \mathrm{~nm}$ to $400 \mathrm{~nm}$ ). However, the EEM spectra extend in an excitation wavelength from $240 \mathrm{~nm}$ to $360 \mathrm{~nm}$ and an emission wavelength from $300 \mathrm{~nm}$ to $500 \mathrm{~nm}$.

It is known, however, that based on EEMs data, the peaks typical for both oils in the two mentioned forms can be described as the peak position of wavelengthindependent fluorescence maximum, written as $\mathrm{Ex}_{\max } /$ $\mathrm{Em}_{\max }[10,11,23]$. We also determined these specific peaks for both kinds of oil dissolved in $\mathrm{n}$-hexane for various oil concentrations. The values of wavelength-independent 

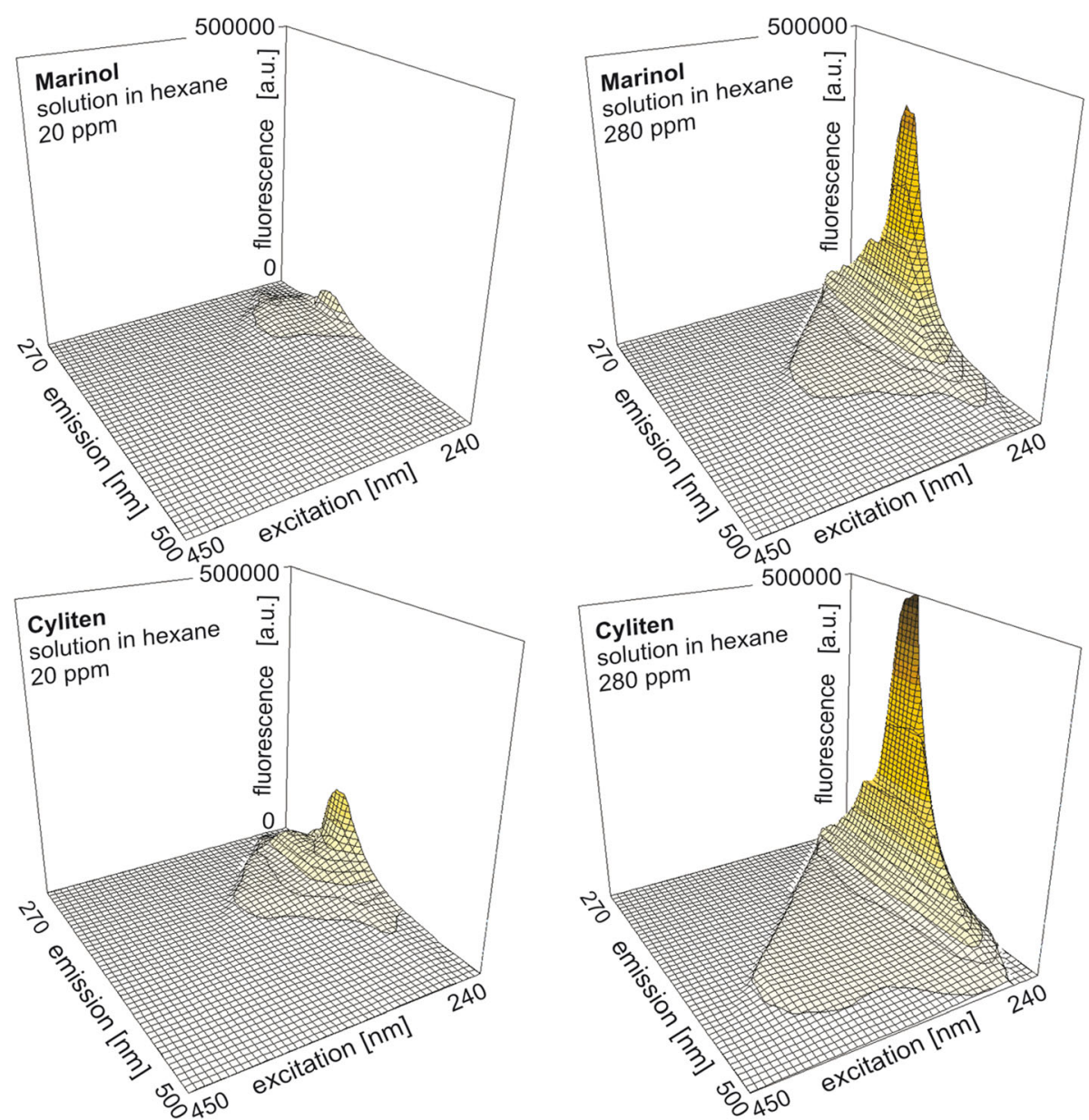

Fig. 2 Excitation-emission fluorescence spectra (EEMs) of oil in n-hexane dilutions for Marinol and Cyliten lubricant oils, in two oil concentrations (20 ppm and $280 \mathrm{ppm}$ ) on the same scale

fluorescence maximum are presented in Table 1. The permanent value of this parameter was observed for different concentrations for both types of oil. However, in Table 2, small variations of wavelength-independent maximum fluorescence are observed for oil-in-water suspensions. Therefore, the wavelength-independent fluorescence maximum may prove to be ineffective in practice.

Excitation-emission spectra of lubricant oils analysed in both forms (Figs. 3 and 4) revealed bands of fluorescence intensity between $300 \mathrm{~nm}$ and $400 \mathrm{~nm}$. These bands appear due to the presence of fluorophores (usually centred in 1-3-ring aromatic structures in the petroleum substances) $[18,24,25]$. The altitude of the peaks depends on the excitation wavelength (Fig. 5) and it is highest for $\lambda_{\mathrm{Ex}}=240 \mathrm{~nm}$ regardless of the oil forms studied. However, it is visible that the width of peaks for oil dispersed in water is wider than for oil in the hexane solution. The selected excitation wavelengths in Fig. 5 are related to excitation wavelengths which induce the fluorescence maxima for some of the natural marine constituents as reported by Coble et al. [11]. This means that the fluorescence spectra of oil partially falls into the range of fluorescence for some natural components of seawater. It should be noted (see Fig. 5) that the intensity of fluorescence for oil dispersed in water is about 10 times lower than for oil dissolved in $n$-hexane (despite the similar concentration of oil).

In view of the above, it would be desirable to find an efficient indicator of oil based on fluorescence spectroscopy which could detect oil in an aquatic environment and possibly identify its type or even origin. Introductory trials to establish an adequate indicator have been conducted [18, 23]. Those studies relied on an analysis of similarities of fluorescence spectra to define if a type of oil can be distinguished by the shape of the EEM spectra (assuming that a database of the spectra of various oils is available). An attempt to explain this matter involves an 


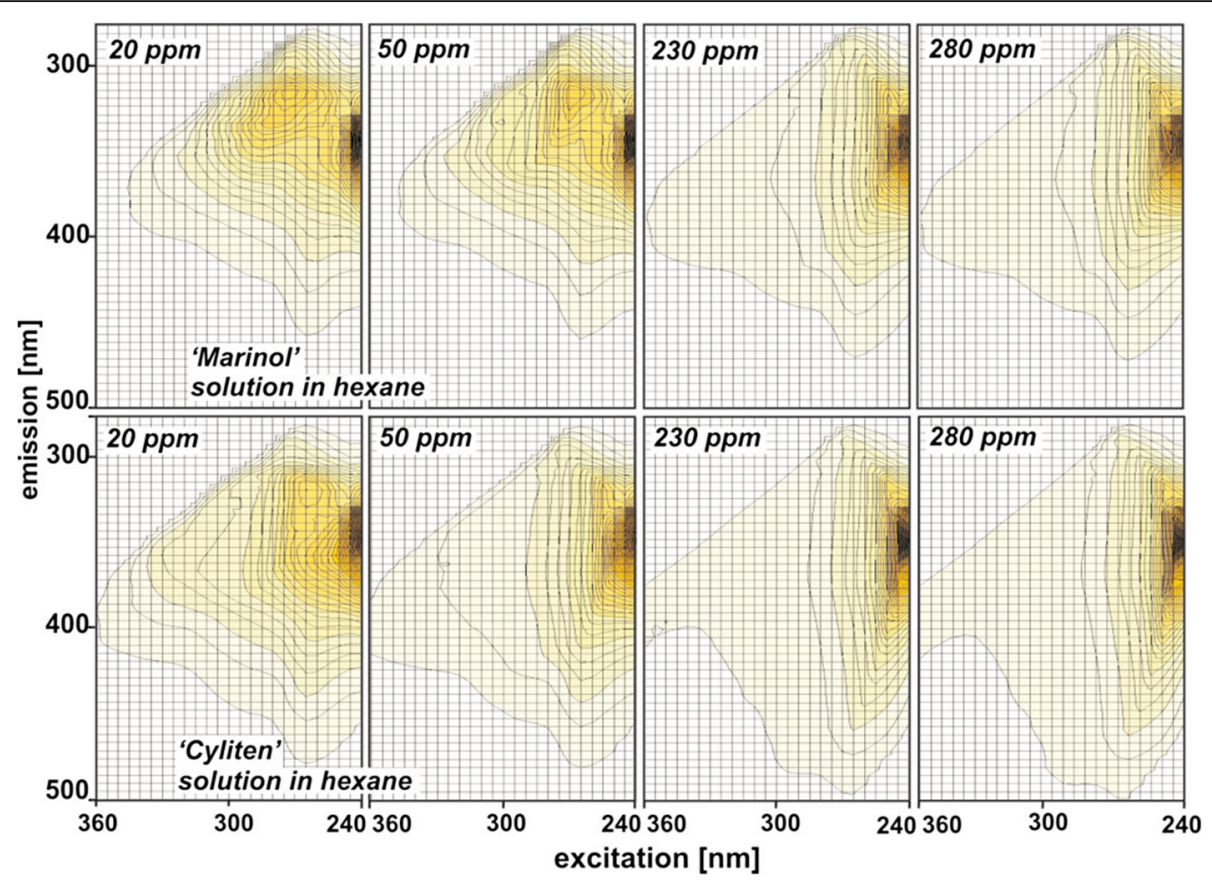

Fig. 3 Normalized EEMs for Marinol and Cyliten in various oil concentrations in n-hexane

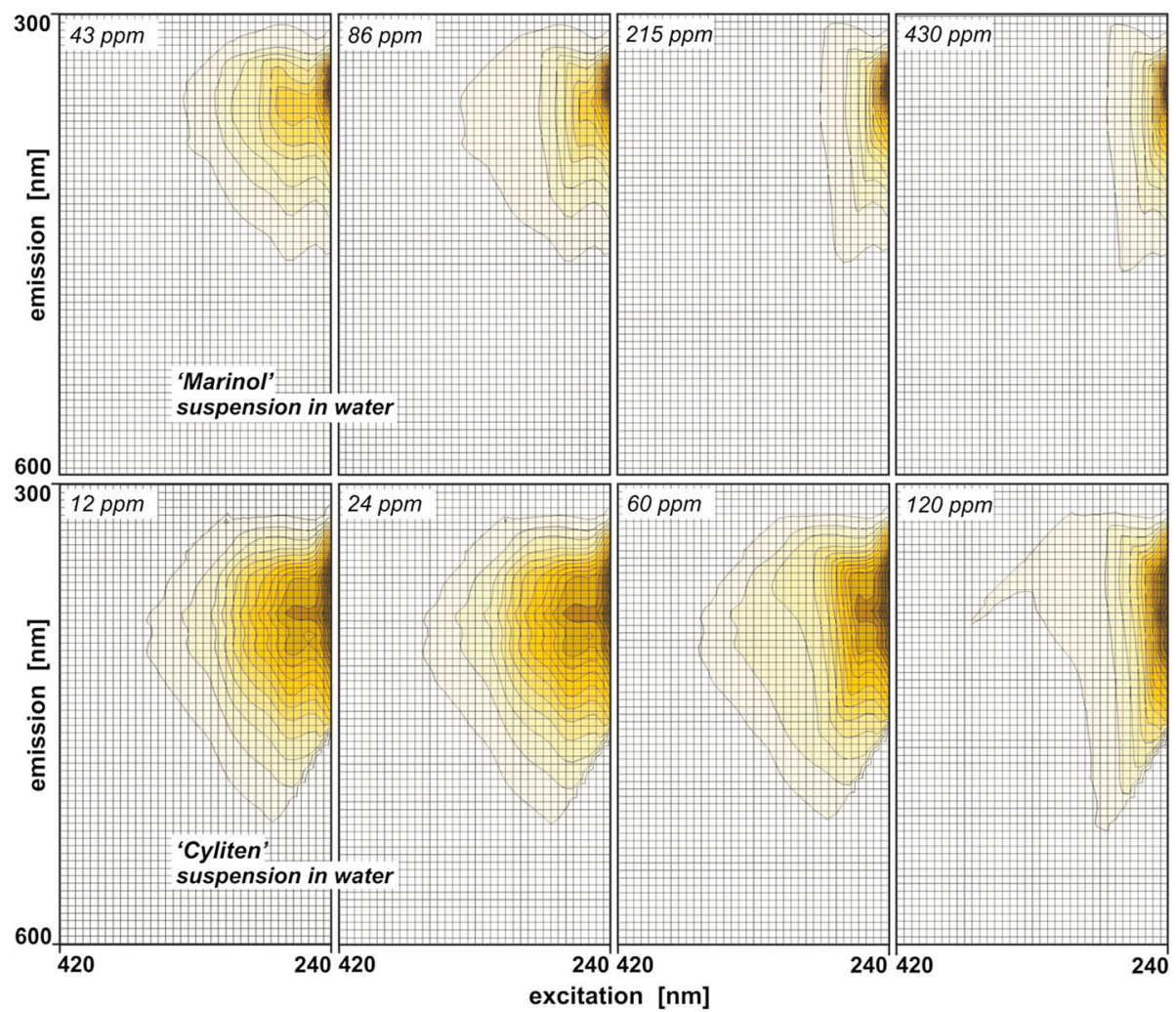

Fig. 4 Total fluorescence spectra of oil dispersed in water (oil-in-water emulsion) for Marinol and Cyliten for various oil concentrations (see Table 2) (redrawn after [22]) 
Table 1 The values for wavelength-independent fluorescence properties of lubricant oil Marinol and Cyliten dissolved in n-hexane described by the fluorescence peak: excitation maximum ( $\left.\mathrm{x}_{\max }\right)$, emission maximum $\left(\mathrm{Em}_{\max }\right)$

\begin{tabular}{llll}
\hline \multicolumn{4}{c}{ Oils dissolved in n-hexane } \\
\hline Marinol & Ex $_{\max } \pm 5[\mathrm{~nm}] / \mathrm{Em}_{\max } \pm 5[\mathrm{~nm}]$ \\
\hline $20 \mathrm{ppm}$ & $242.5 / 335.3$ & $20 \mathrm{ppm}$ & $242.5 / 348$ \\
$50 \mathrm{ppm}$ & $242.5 / 335.3$ & $50 \mathrm{ppm}$ & $242.5 / 348$ \\
$230 \mathrm{ppm}$ & $242.5 / 335.3$ & $230 \mathrm{ppm}$ & $242.5 / 348$ \\
$280 \mathrm{ppm}$ & $242.5 / 335.3$ & $280 \mathrm{ppm}$ & $242.5 / 348$ \\
\hline
\end{tabular}

Table 2 The values for wavelength-independent fluorescence properties of lubricant oil Marinol and Cyliten dispersed in water described by the fluorescence peak: excitation maximum $\left(\right.$ Ex $\left._{\max }\right)$, emission maximum (Em $\left.m_{\max }\right)$

\begin{tabular}{llll}
\hline \multicolumn{4}{c}{ Oils dispersed in water } \\
\hline Marinol & Ex $_{\max } \pm 5[\mathrm{~nm}] / \mathrm{Em}_{\max } \pm 5[\mathrm{~nm}]$ \\
\hline $43 \mathrm{ppm}$ & $242.5 / 348.32$ & $12 \mathrm{ppm}$ & $242.5 / 387.6$ \\
$86 \mathrm{ppm}$ & $242.5 / 350$ & $24 \mathrm{ppm}$ & $242.5 / 385.9$ \\
$215 \mathrm{ppm}$ & $242.5 / 350$ & $60 \mathrm{ppm}$ & $242.5 / 385.9$ \\
$430 \mathrm{ppm}$ & $242.5 / 350$ & $120 \mathrm{ppm}$ & $242.5 / 385.9$ \\
\hline
\end{tabular}

analysis of to what extent the similarity ratio $\mathrm{s}_{\mathrm{ab}}$ - defined by formula (1) - depends on the oil concentration.

Since the $s_{a b}$ value diagram in Fig. 6 demonstrates that the similarity between the spectra of the same type of oil significantly decreases with a greater difference in oil concentrations (despite the fact that the spectra were normalised) it would be difficult to recognize the

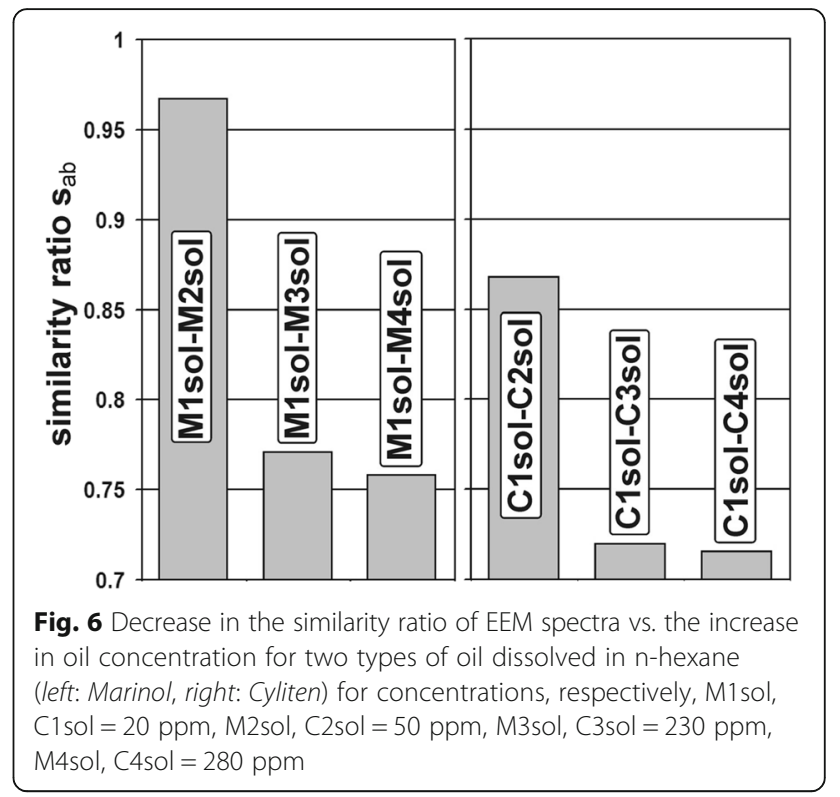

type of oil by comparing the entire EEM spectra. For this reason, we sought another spectral indicator of the presence of oil, which was "insensitive" to the oil concentration, following the example of Budgen et al. [18], who based on EEM spectra, defined the "intensity ratio" parameter as the quotient of the fluorescence intensities for two defined emission wavelengths (corresponding to the detected emission maxima), consistent with the appropriate excitation wavelength, which allows oils to be detected without the necessity of measuring oil concentrations. Taking into account this approach using the determined EEMs of lubricate oils for each oil concentration, excitation and emission wavelengths were selected to determine the "intensity ratio", which is an oil-concentration-independent parameter. The intensity ratio $\left(I_{\text {ratio }}\right)$ for each oil

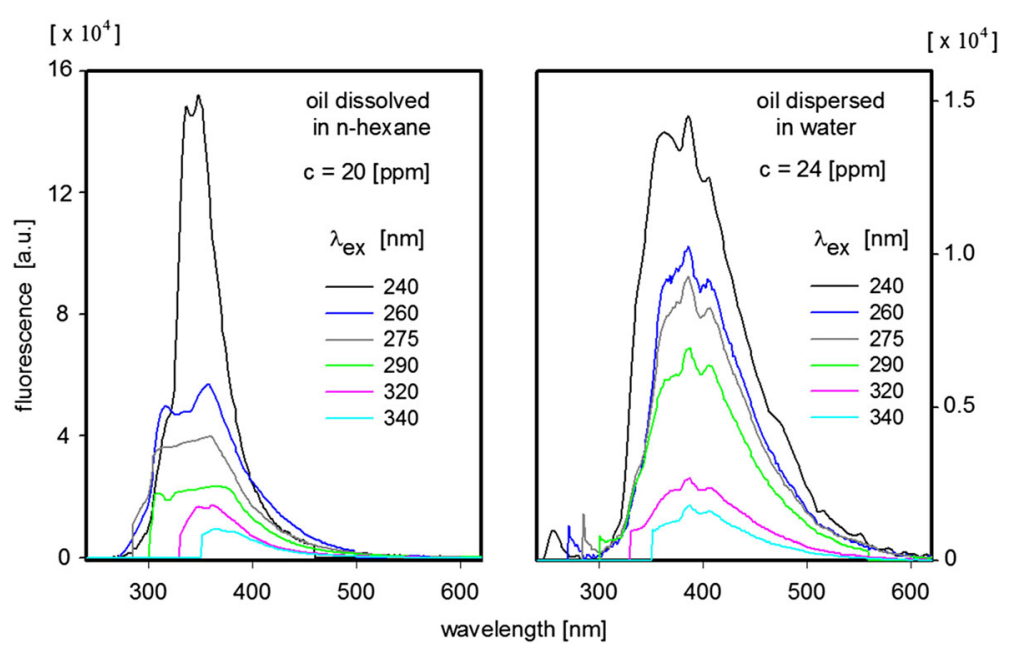

Fig. 5 Fluorescence spectra of sample lubricant oil (Cyliten) dissolved in $n$-hexane (left) and dispersed in water (right) for various excitation wavelengths applied to analyse the constituents of natural seawater [11] 


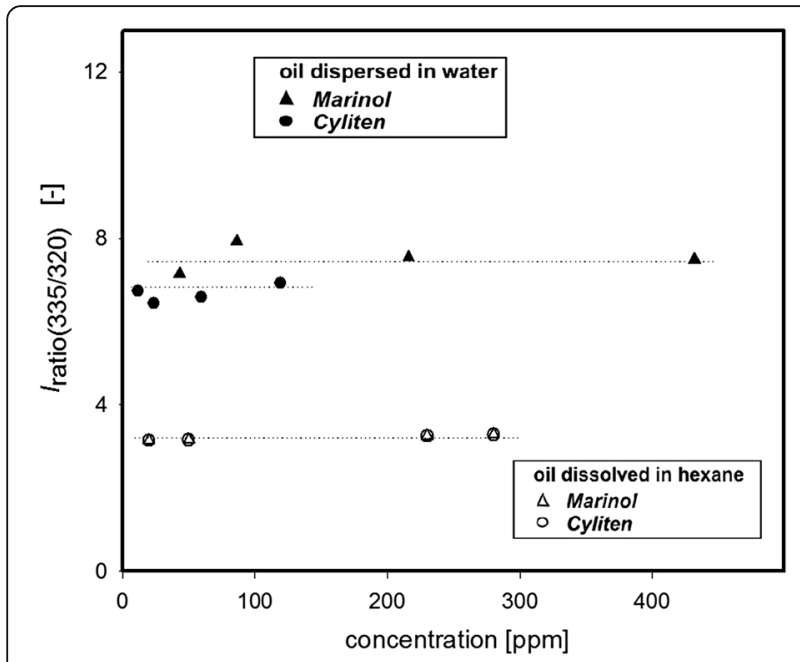

Fig. 7 Intensity ratio (expressed by formula 2) as a function of oil concentration for oil dispersed in water and dissolved in $n$-hexane

concentration was calculated as the ratio of the fluorescence intensity at a $335 \mathrm{~nm}$ emission wavelength to an intensity of $320 \mathrm{~nm}$, while the excitation wavelength remained equal to $242.5 \mathrm{~nm}$ (expressed by formula 2). In this case, the determined $I_{\text {ratio }}$ was relatively stable, regardless of the oil concentration for the studied cases.

For calculation of the intensity ratio parameter, the choice of the excitation and emission wavelength was dictated by the specific peaks detected in the EEM spectrum. Therefore, the intensity ratio calculations were performed taking into account the maximum intensities between the principal emission bands identified at $335 \mathrm{~nm}$ (for this wavelength the independence from the oil concentration is fulfilled) and a second smaller band identified at $320 \mathrm{~nm}$. Moreover, the choice of the excitation wavelength at $242.5 \mathrm{~nm}$ was caused due to the position of all of the principal identified bands corresponding to this one excitation wavelength.

However, when interpreting the results shown in Fig. 7, it can be assumed that the wavelengths chosen for excitation and emission are suitable for an intensity ratio $\left(I_{\text {ratio }}\right)$ for lubricating oil dispersed in water, regardless of the oil concentration.

Budgen et al. [18] also analysed other types of oils (characterized by various viscosity) and suggested other wavelengths. However, those tests concerned only one concentration of oil. In the current stage of studies, it would be premature to operationally apply intensity ratio because it is necessary to broaden the knowledge of the fluorescence of the natural constituents of seawater, which can deform the EEM spectra of oil. There are laboratory procedures which have been applied to describe the components of seawater based on EEMs $[8,10,14]$ and a review of a sample group of potential seawater components was provided by Coble [11]. Moreover, a clear and detailed description of CDOM based on EEMs was also described by Coble $[10,11]$. In the EEM spectra, separated peaks were identified and described by so-called wavelength-independent maxima as amino acid-like, humic acids and fulvic acids (Table 3). Moreover, the potential component of seawater are residues of crude oils and other petroleum derivatives, among others, aromatic polycyclic hydrocarbon compounds (PAHs) which contains fluorescence centres. The fluorophore components of petroleum substances can disturb the fluorescence of seawater natural constituents.

Using the obtained EEM spectra for lubricate oils, the range of changes of $\mathrm{Ex}_{\max } / \mathrm{Em}_{\max }$ for both types of studied oils dispersed in water were determined for all variation ranges of this parameter provided in Table 2 for Marinol $(242.5 \mathrm{~nm} / 350 \mathrm{~nm})$ and Cyliten $(242.5 \mathrm{~nm} /$ $386 \mathrm{~nm})$. The juxtaposition of values of $\mathrm{Ex}_{\max } / \mathrm{Em}_{\max }$ for lubricant oils with values of this parameter for various seawater constituents is shown in Fig. 8. In this figure, it is noticeable that $\mathrm{Ex}_{\max }$ for lubricant oils is shifted to lower wavelengths in relation to $\mathrm{Ex}_{\max }$ for natural seawater constituents, although $\mathrm{Em}_{\max }$ partially overlaps $\mathrm{Em}_{\max }$ for seawater constituents. It is also clear that $\mathrm{Ex}_{\max }$ for $242.5 \mathrm{~nm}$ (and presumably for lower excitation wavelengths) allows the excitation component originating from natural seawater constituents to be eliminated. In summary, this solution will probably allow the discrimination of oil residues from seawater fluorescent substances, although creating a final operational method requires further studies using natural seawater.

\section{Conclusions}

Detecting oil substances appearing in small concentrations in natural waters requires an efficient indicator insensitive to the fluorescent substances naturally residing in the aquatic environment. It is confirmed that the use of the wavelength-independent maximum procedure is very promising, even in a low oil concentration and the influence of concentration turns out to be irrelevant.

In high oil concentrations (more than several ppm), the spectrum is dominated by the fluorescence of an oil

Table 3 Major fluorescent components of seawater with their wavelength-independent maxima [11]

\begin{tabular}{ll}
\hline Seawater component & $E x_{\max }[\mathrm{nm}] / E m_{\max }[\mathrm{nm}]$ \\
\hline Tyrosine-like & $275 / 305$ \\
Tryptophan-like & $275 / 340$ \\
UVC-humic-like & $260 / 400-460$ \\
UVA-humic-like & $320-360 / 420-460$ \\
Marine humic-like & $290-310 / 370-410$ \\
Pigment-like & $398 / 660$ \\
\hline
\end{tabular}




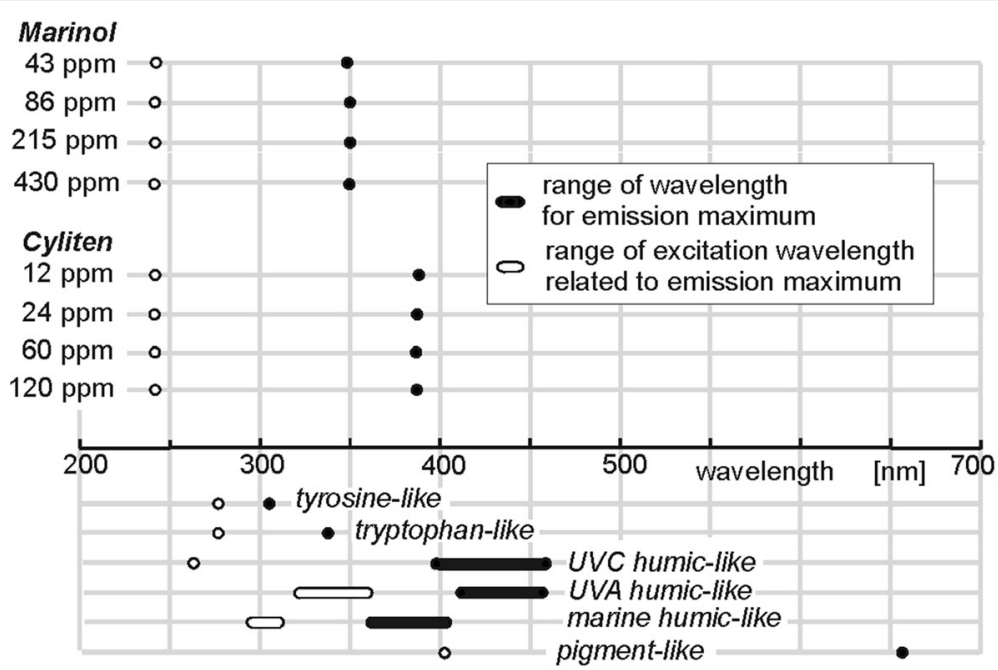

Fig. 8 Juxtaposition of lubricating oils suspended in water with various marine constituents (as described by Coble [1 1]) for wavelength-independent maximum $\mathrm{Ex}_{\max } / \mathrm{Em}_{\max }$

substance. In such a situation, it is necessary to be sure that pollution is really an oil substance. Methods for oil identification as described in this paper using a similarity ratio are of rather little use because the shape of the EEM depends on the concentration of oil. Fortunately, the proposed intensity ratio appears to be independent of oil concentration (in analysed concentrations from zero to several hundred ppm).

The presented results indicate that it is worth expanding knowledge of the spectroscopic features of natural and human-made marine constituents to improve the efficiency of the interpretation of fluorescence spectra for detection and identification of substances considered as pollution. It is also worth mentioning that oil pollution can disturb fluorescent indices used in the tracking of biological processes in an aquatic environment.

\section{Abbreviations}

EEM: Excitation-emission; EEMs: Excitation-emission spectra; Em max: Emission maximum; Ex max: Excitation maximum; Iratio: Intensity ratio

\section{Acknowledgements}

We would like to thank Oliver Zielinski from the Institute of Chemistry and Biology of the Marine Environment at the University of Oldenburg for making the measuring equipment available.

\section{Funding}

This paper was supported by Gdynia Maritime University grant No. DS/427/2016.

\section{Authors' contributions}

Both authors contributed equally in all the sections of this work.

\section{Competing interests}

The authors declare that they have no competing interests.

Received: 16 May 2016 Accepted: 20 September 2016 Published online: 03 October 2016

\section{References}

1. Fingas, $M$, Brown, CE: Oil Spill Remote Sensing. In: Fingas, M (ed.) Handbook of Oil Spill Science and Technology, 1st edn, pp. 313-347. (2015)

2. EMSA. Oil spill detection examples: Maersk Kiera: February (2012). http://www.emsa.europa.eu/csn-menu/csn-service/oil-spill-detectionexamples.html. Accessed 16 Oct 2013.

3. Migliaccio, M, Gambardella, A, Tranfaglia, M: SAR polarimetry to observe oil spills. IEEE Trans. Geosci. Remote Sens. 43(2), 506-511 (2007)

4. Robbe, N, Zielinski, O: Airborne remote sensing of oil spills- analysis and fusion of multi spectral near-range data. J. Mar. Sci. Environ. C2, 19-27 (2004)

5. Kienhuis, PGM, Dahlmann, G: Second Intercalibration Round in the Framework in of Bonn OSINET-Round Robin 2007, The Comparison of Six HFO Samples: The Results of Nineteen International Laboratories, File No. 2007. WIL23x, Bonn-OSINet, London, 1, (2007)

6. Albaigés, J, Kienhuis, PGM, Dahlmann, G: Oil Spill Identification. Chapter 6 . In: Handbook of Oil Spill Science and Technology, Firstth edn. Wiley, Hoboken (2015)

7. Geddes, CD, Lakowicz, JR: Review in fluorescence, vol. 2. Springer, Berlin (2005)

8. Stedmon, CA, Markager, S, Bro, R: Tracing dissolved organic matter in aquatic environments using a new approach to fluorescence spectroscopy. Mar. Chem. 82, 239-254 (2003)

9. Stedmon, CA, Markager, S, Tranvik, L, Kronberg, L, Slätis, T, Martinsen, W: Photochemical production of ammonium and transformation of dissolved organic matter in the Baltic Sea. Mar. Chem. 104, 227-240 (2007)

10. Coble, PG: Characterization of marine and terrestrial DOM in seawater using excitation emission matrix spectroscopy. Mar. Chem. 51(4), 325-346 (1996)

11. Coble, PG: Marine optical biogeochemistry: the chemistry of ocean color. Chem. Rev. 107(2), 402-418 (2007)

12. Coble, PG: Colored dissolved organic matter in seawater. In: Watson, J., Zielinski, O (eds.) Subsea Optics and Imaging, 1st edn, pp. 98-119. Woodhead Publishing, Cambridge (2015)

13. Drozdowska, V, Józefowicz, M: Spectroscopic studies of marine surfactants in the southern Baltic Sea. Oceanologia 57(1), 159-167 (2015)

14. Kowalczuk, P, Ston-Egiert, J, Cooper, WJ, Whitehead, RF, Durako, MJ: Characterization of chromophoric dissolved organic matter (CDOM) in the Baltic Sea by excitation emission matrix fluorescence spectroscopy. Mar. Chem. 96(3-4), 273-292 (2005)

15. Christensen, JH, Hansen, AB, Mortensen, J, Andersen, O: Characterization and matching of oil samples using fluorescence spectroscopy and parallel factor analysis. Anal. Chem. 77(7), 2210-2217 (2005)

16. Baszanowska, E, Otremba, Z, Toczek, H, Rohde, P: Fluorescence spectra of oil after it contacts with aquatic environment. J. KONES Powertrain Trans. 20(3), 29-34 (2013) 
17. Baszanowska, E, Otremba, Z, Rohde, P, Zieliński, O: Adoption of the time resolved fluorescence to oil type identification. J. KONES Powertrain Trans. $18(2), 25-29$ (2011)

18. Bugden, JBC, Yeung, CW, Kepkay, PE, Lee, K: Application of ultraviolet fluorometry and excitation-emission matrix spectroscopy (EEMs) to fingerprint oil and chemically dispersed oil in seawater. Mar. Poll. Bull. $56,677-685$ (2008)

19. Kepkay, PE, Bugden, JBC, Lee, K, Stoffyn-Egli, P: Application of ultraviolet fluorescence spectroscopy to monitor oil-mineral aggregate formation. Spill Sci. Tech. Bull. 8(1), 101-108 (2002)

20. Ostrowska, M: Model dependences of the deactivation of phytoplankton pigment excitation energy on environmental conditions in the sea. Oceanologia 54(4), 545-564 (2012)

21. Stelmaszewski, A: Petroleum in coastal seawater of Gdansk Bay. Oceanol. Hydrobiol. Stud. 44(1), 87-96 (2015)

22. Baszanowska, E, Zielinski, O, Otremba, Z, Toczek, H: Influence of oilin-water emulsions on fluorescence properties as observed by excitation-emission spectra. J. Europ. Opt. Soc. Rap. Public. 8, 13069 (2013). doi:10.2971/jeos.2013.13069

23. Baszanowska, E, Otremba, Z: Spectral signatures of fluorescence and light absorption to identify crude oils found in the marine environment. J. Europ. Opt. Soc. Rap. Public. 9, 14029 (2014). doi:10.2971/jeos.2014.14029

24. Guilbault, GG (ed.): Practical fluorescence. CRC Press, New York (1990)

25. Wakeman, SG: Synchronous fluorescence spectroscopy and its application to indigenous and petroleum-derived hydrocarbons in lacustrine sediments. Environ. Sci. Technol. 11, 272-276 (1977)

\section{Submit your manuscript to a SpringerOpen ${ }^{\circ}$ journal and benefit from:}

- Convenient online submission

- Rigorous peer review

- Immediate publication on acceptance

- Open access: articles freely available online

- High visibility within the field

- Retaining the copyright to your article 